\title{
THEORETICAL-METHODOLOGICAL CONSIDERATIONS ON MAXIMIZING THE EFFECTS OF ARM STRIKES IN CONTACT SPORTS IN MILITARY PHYSICAL EDUCATION
}

\author{
Robert STĂNCIULESCU \\ rstanciulescu@armyacademy.ro \\ “NICOLAE BĂLCESCU” LAND FORCES ACADEMY, SIBIU, ROMANIA
}

\begin{abstract}
Due to the complex, unique, multiple demands they exert on the human body through the skills, competences and abilities, they develop as well as by contributing to the development of motor skills, fighting sports represent an effective way of preparing the military to respond to the rigors imposed by the modern war. The strikes with arms and with auxiliary equipment (light weapons, bayonets, raffles, daggers or small shovels) are part of the basic techniques used in close fight, which, if well-mastered, developed and perfected, contribute to the success of the battle.
\end{abstract}

\section{KEYWORDS:}

Sport, fight, strike, action, effort.

\section{Introduction}

The performance level of the military personnel while exercising their profession is directly proportional to the capabilities they possess and is a direct consequence of their training. The motor performance of fighters in crisis and war situations has as a factor the knowledge, the attitudes, the skills and the abilities outlined through the activities of military physical training and achieved through a well-planned educational process organized and carried out in accordance with the requests of the third millennium war (Stănciulescu, 2017). The whole process of military students training aims at optimizing professional training and includes military physical education as one of the pillars supporting the training process, alongside military and academic training. This discipline, based on scientific and solid information, pursued systematically and continuously, aims at developing the motor skills at an optimal level, at improving the basic, applicative motor skills, so as to provide sufficient physical and psychological potential for the accomplishment of individual and team missions for extended periods of time and space in any terrain, climate, season or weather conditions. As a pillar of the training process, military physical education involves bravery and will, a great use of forces, an intense 
creative activity, precision and accuracy, observance of a rigorous working and living style, all in the context of irreproachable order and discipline. Developing the professional competences to the level and the requirements imposed by the military institution, the physical education, besides optimizing the motor capacity aims at forming the routine of systematic exercise all along the military career, and even afterwards, facilitating the harmonious physical development and maintaining an optimal state of health. At the same time, it ensures the development of moral traits and the specific will of the fighter, and contributes to the development of the military personality in terms of character.

\section{Combat and self-defense sports in military physical education}

Disciplines with high emotional impact, combat sports mainly aim at the development and improvement of skills and competencies with applicability in the complex actions of close combat, of diversion and anti-diversion, as well as in the fight in which the fire of the individual weapon cannot be used. Really contributing to the increase of fighters' combativeness by developing basic motor skills, psychic qualities of coordination and selfindulgence in front of the factors that cause pain and fear, and courage and confidence in their own strengths, combat and selfdefense sports develop skills and qualities absolutely necessary to conduct successful fighting actions, isolated or in group, in any geoclimatic conditions (Stănciulescu, 2008). Developing skills to attack, block and counterattack with the bare hands or with the individual weapons, the purpose is to develop the skills of fighting against several armed opponents. Judo and jiu-jitsu, taekwondo, karate, or close combat with light weapons are disciplines whose wellperfected and executed procedures have multiple effects on combat ability, effectively contributing to the development of a highly skilled human resource, capable of efficiently managing the military action.

\subsection{Arm strikes in close combat}

The main motor elements in combat sports are the strikes, which are the expression of the physical and psychological activity of the fighters. The main objective in these sports is the efficiency of the strikes and the interdependence of movements reported to the opponent as the target that can react and perform counter-action moves. The strikes, regardless of their nature, with arms, legs or combat equipment (light weapons, bayonets, tonfa daggers or small shovels) must be executed in sensitive areas, not necessarily with maximum force as with the increased execution speed. To be effective, they need precision, as little energy as possible, and to be executed on the largest, yet the most sensitive surfaces. The body must always be in perfect balance, avoiding the exaggerated trunk, pelvis or legs bending, as well as twists that affect precision. It should permanently be taken into account that the opponent is not a fixed target but a moving one, and that he can counterattack at any time. It is therefore necessary to consider the fact that, besides the dynamic activity of overcoming resistance, where the muscular system engaged in activity aims at transforming a series of motor actions in effective strikes executed with force and speed, the body makes a considerable effort to ensure the balance (Hantău, 2005). 


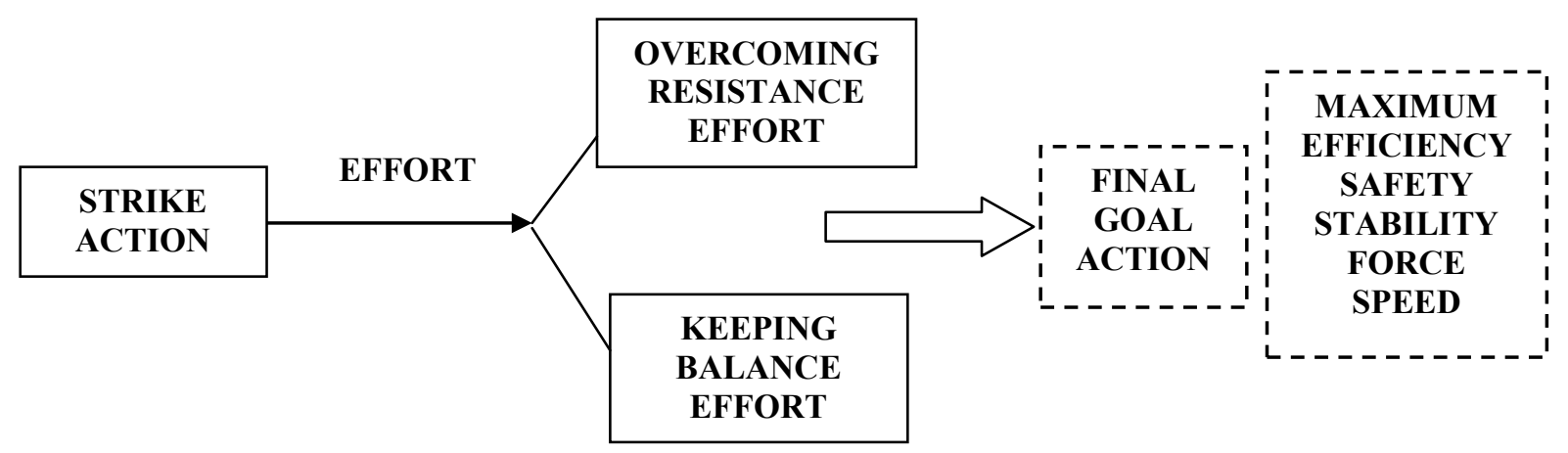

Figure no. 1 Courses of action of the effort

The strikes with arms or with auxiliary equipment can be of various types:

\section{a) Direct blows}

They are a combination of static activity and the dynamic activity of important muscle chains that effectively harmonize the activity of the muscles of the upper limbs with those of the trunk and legs. Therefore, it is necessary to consider the development of the muscular groups involved in the activity, namely the extensor muscles of the elbow, the abductor and adductor muscles of the arm, the ventral muscle chains of the trunk, the muscles of the abdominal walls, as well as the lower limb muscles that make the impulsion. In this type of strikes, the support is usually done on one of the legs that must go back to the initial position in an elastic way, after the strike. During training, one should not neglect the importance of the joints of the fist and of the elbow, and the scapular belt of the trunk. A good execution of the direct strikes should not affect, in any way, the balance. This type of strikes usually apply to the head, chest, abdomen or upper and lower limbs. The initial position when applying this type of strike should be a relaxed one, in which the weight of the body is equally distributed on both legs.

\section{b) Side blows}

They usually apply to the head, carotid, liver or upper and lower limbs. As they involve a large twist of the hips while the weight of the body goes harmoniously from one leg to the other, they are highly effective. From the initial position, the right or left leg turns on the direction of the blow, followed by the hip and trunk, then the upper limb, which by a circular twist, engages the shoulder before which, in turn, engages the arm bent with the elbow parallel to the ground in an elastic movement but executed with speed and force. The shoulder should not exceed the hip line and, together with the arm and trunk, should form a semicircle. The side blows are practically structured on three moments, which in turn, are composed of circular contractions of the muscular system. In the first moment, a sudden rotation of the hip is carried out; its support is the leg on the side of the blow. The next moment is the turning of the shoulders, and finally the contact with the opponent occurs, at which time the muscular chains involved in the striking activity are stretched to the maximum. It then follows the recovery movement in a natural way, and the transfer of weight on both legs. When using auxiliary equipment, it must be held in the most energetic but comfortable way, so that the strike is perfectly oriented towards the impact area. An extremely important role in optimizing this type of blow is the preparatory phase that creates the conditions for performing an effective blow and ensures the balance through the stability of the body by identifying the best support base. In the preparatory phase we should also try to identify the favorable moment for the execution of the strike, 
more specifically the best distance to execute the blow, the best execution angle, or the uncovered area of the opponent. Of course during the execution of the strikes it is necessary to consider that the opponent can counterattack. Thus, it is necessary to observe with great care his activity, in order to timely notice his intention to counterattack and move to an active character of defense, through evasions and defense elements (Hantău, 2005). This requires a high reaction speed and high nervous coordination, but they are extremely effective as they save energy and create the conditions for counterattack, by surprising and demoralizing the opponent.

\section{Conclusions}

As a conclusion, it is necessary to mention that for the increased efficiency of the specific blows we have to obtain a nervous coordination as precise as possible, a speed of execution and reaction as high as possible, and the appropriate equilibrium capacity, all on the background of an exceptional physical and psychological resistance (Danovschi, 1990). This aspect must be taken into account, so that the training system constantly works to optimize the level of physical and psychological training; given the fact that there is a tight relationship between these two components, they are mutually dependent and have an essential role in getting the desired effects. The development and the improvement of the combat skills specific to these sport disciplines are extremely valuable, contributing substantially to the achievement of an increased fighting capacity, adapted to the rigors imposed by the new type of the highly demanding war of this millennium.

\section{REFERENCES}

Hantău, I. (2005). Teoria şi metodica judoului, Bucureşti: Printech.

Danovschi, V.C. (1990). Pregătirea luptătorilor de mare performanță, Sportul de performanță, 306-307.

Stănciulescu, R. (2008). Sporturi de luptă în educația fizică militară, Sibiu: Editura Academiei Forțelor Terestre "Nicolae Bălcescu".

Stănciulescu, R. (2017). Didactica activităților fizice cu caracter aplicativ-militar, Sibiu: Editura Academiei Forțelor Terestre "Nicolae Bălcescu". 